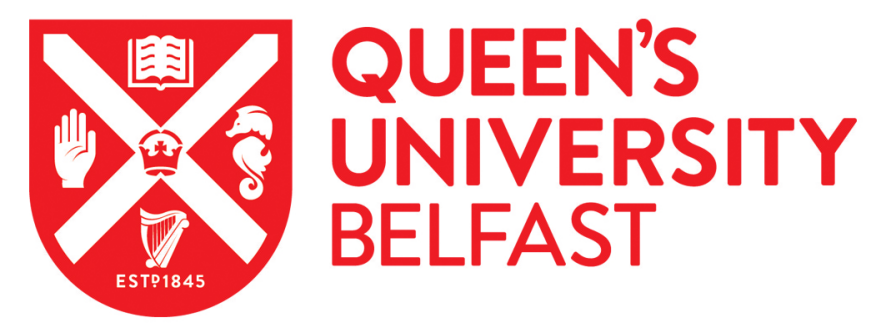

\title{
Implementation of a cogeneration plant for a food processing facility. A case study
}

Bianco, V., De Rosa, M., Scarpa, F., \& Tagliafico, L. A. (2016). Implementation of a cogeneration plant for a food processing facility. A case study. Applied Thermal Engineering, 102, 500-512.

https://doi.org/10.1016/j.applthermaleng.2016.04.023

Published in:

Applied Thermal Engineering

Document Version:

Peer reviewed version

Queen's University Belfast - Research Portal:

Link to publication record in Queen's University Belfast Research Portal

Publisher rights

(c) 2016 Elsevier B.V. This manuscript version is made available under the CC-BY-NC-ND 4.0 license

http://creativecommons.org/licenses/by-nc-nd/4.0/, which permits users to copy and distribute the work as long as they do not change it or create derivative works or use it for commercial purposes.

\section{General rights}

Copyright for the publications made accessible via the Queen's University Belfast Research Portal is retained by the author(s) and / or other copyright owners and it is a condition of accessing these publications that users recognise and abide by the legal requirements associated with these rights.

Take down policy

The Research Portal is Queen's institutional repository that provides access to Queen's research output. Every effort has been made to ensure that content in the Research Portal does not infringe any person's rights, or applicable UK laws. If you discover content in the Research Portal that you believe breaches copyright or violates any law, please contact openaccess@qub.ac.uk. 


\section{Accepted Manuscript}

Implementation of a cogeneration plant for a food processing facility. A case of study

Vincenzo Bianco, Mattia De Rosa, Federico Scarpa, Luca A. Tagliafico

PII:

S1359-4311(16)30509-9

DOI: http://dx.doi.org/10.1016/j.applthermaleng.2016.04.023

Reference: ATE 8069

To appear in:

Applied Thermal Engineering

\section{APPLIED}

THERMAL

ENGINEERING

\section{(as)}

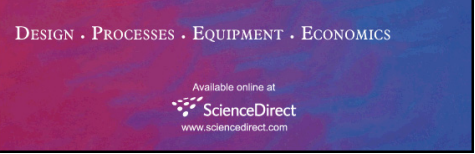

Received Date: 13 January 2016

Accepted Date: $\quad 5$ April 2016

Please cite this article as: V. Bianco, M.D. Rosa, F. Scarpa, L.A. Tagliafico, Implementation of a cogeneration plant for a food processing facility. A case of study, Applied Thermal Engineering (2016), doi: http://dx.doi.org/10.1016/ j.applthermaleng.2016.04.023

This is a PDF file of an unedited manuscript that has been accepted for publication. As a service to our customers we are providing this early version of the manuscript. The manuscript will undergo copyediting, typesetting, and review of the resulting proof before it is published in its final form. Please note that during the production process errors may be discovered which could affect the content, and all legal disclaimers that apply to the journal pertain. 


\title{
Implementation of a cogeneration plant for a food processing facility. A case of
} study.

Vincenzo Bianco ${ }^{1, *}$, Mattia De Rosa ${ }^{2}$, Federico Scarpa $^{1}$, Luca A. Tagliafico ${ }^{1}$

${ }^{1}$ University of Genoa - DIME/TEC, Division of Thermal Energy and Environmental Conditioning. Via All'Opera Pia 15/A - 16145 Genova - Italy

${ }^{2}$ School of Mechanical and Aerospace Engineering, Queen's University Belfast. Ashby Building, Stranmillis Road, BT9 5AG, Belfast. United Kingdom.

*Corresponding Author: phone: +39 010353 2872; e-mail: vincenzo.bianco@unige.it

\begin{abstract}
The present work presents an investigation regarding the feasibility analysis of a cogeneration plant for a food processing facility with the aim to decrease the cost of energy supply. The monthly electricity and heat consumption profiles are analysed, in order to understand the consumption profiles, as well as the costs of the current furniture of electricity and gas. Then, a detailed thermodynamic model of the cogeneration cycle is implemented and the investment costs are linked to the thermodynamic variables by means of cost functions. The optimal electricity power of the cogenerator is determined with reference to various investment indexes. The analysis highlights that the optimal dimension varies according to the chosen indicator, therefore it is not possible to establish it univocally, but it depends on the financial/economic strategy of the company through the considered investment index.

Keywords: cogeneration, energy efficiency, natural gas, electricity
\end{abstract}

\author{
Nomenclature \\ C Cost $(\$, €)$ \\ CF Cash flow $(\$, €)$ \\ CHP combined heat power \\ COND condenser \\ CV variable costs $(\$, €)$ \\ DCF Discounted cash flow $(\$, €)$ \\ $\Delta \mathrm{T}_{\mathrm{ml}} \quad$ Mean logarithmic temperature $(\mathrm{K})$ \\ E Exergy (kJ kg-1) \\ $\mathrm{El} / \mathrm{el}$ Electricity \\ ECO Economizer
}


EF Emission factor (ton $\mathrm{MWht}^{-1}$ )

EVA Evaporator

GT gas turbine

h Enthalpy (kJ kg-1)

HRSG Heat Recovery Steam Generator

i year index / ideal

I Destroyed exergy (kJ kg-1)

INV Investment cost (\$,€)

IRR Internal rate of return

LHV Low heating value $\left(\mathrm{kJ} \mathrm{kg}^{-1} \mathrm{~K}^{-1}\right)$

$\dot{m} \quad$ Mass flow rate $\left(\mathrm{kg} \mathrm{s}^{-1}\right)$

$\mathrm{N} \quad$ Plant operating life

NPV Net present value (\$,€)

$\mathrm{P} \quad$ Power $(\mathrm{kW})$

PEC Purchase Equipment Cost $(\$, €)$

PES Primary energy savings

PI Profitability index

Q Thermal power $(\mathrm{kW})$

$\mathrm{r} \quad$ Discount rate (\%)

s,S Entropy (kJ kg-1 K-1)

ST Steam cycle

$\mathrm{T}$ Temperature $\left({ }^{\circ} \mathrm{C}\right)$

VOM Variable Operating Costs $(\$, €)$

y number of years

W Work $\left(\mathrm{kJ} \mathrm{kg}^{-1}\right)$

Greek Letters

$\beta \quad$ Compression ratio

$\eta \quad$ Efficiency

$\eta_{\mathrm{I}} \quad$ First law efficiency

$\eta_{\mathrm{ex}} \quad$ Second law efficiency

\section{Subscripts}

0 reference value 


$\begin{array}{ll}\text { a } & \text { air } \\ \text { aph } & \text { air pre-heater } \\ \text { c } & \text { compressor } \\ \text { cc } & \text { combustion chamber } \\ \text { el } & \text { electrical } \\ \text { ex } & \text { existing situation } \\ \text { g } & \text { gas } \\ \text { gen } & \text { generated } \\ \text { GT } & \text { gas turbine } \\ \text { I } & \text { inlet } \\ \text { imp } & \text { import } \\ \text { int } & \text { integration } \\ \text { mech } & \text { mechanical } \\ \text { NG } & \text { natural gas } \\ \text { o } & \text { outlet } \\ \text { p } & \text { pump } \\ \text { ref } & \text { reference state/value } \\ \text { rg } & \text { regenerator } \\ \mathrm{t} & \text { turbine } \\ \text { w } & \text { water }\end{array}$

\section{Introduction}

During the past ten years, EU has strongly enforced its strengths to develop an advanced and effective energy efficiency policy. In fact, a substantial regulatory framework has been released to set up specific targets and regulate the different interventions.

In October 2012, the new Energy Efficiency Directive [1] was emanated. It includes provisions on the setting of energy efficiency targets in the manufacturing sector (Art. 3), general energy efficiency policies (e.g. the introduction of energy efficiency obligations or equivalent measures in Art. 7) and measures addressing specific sectors as e.g. buildings (Art. 4 and 5), energy audits and management systems for enterprises (Art. 8) or CHP (Art. 14).

Cogeneration is an efficient way of generating electrical energy and heat simultaneously from a given amount of fuel. Primary energy savings can be relevant if compared to the separate generation of heat and electricity and, as a consequence, the environmental footprint of production processes is improved, because the consumption of resources and the emissions of pollutants are reduced. For 
these reasons, cogeneration is also acknowledged as an important tool to meet the requirements of the Kyoto protocol. According to Cakir et al. [2], CHP may result in a consistent energy conservation (usually ranging from $10 \%$ to $30 \%$ ) while the avoided $\mathrm{CO}_{2}$ emissions are, as a first approximation, similar to the amount of energy saving.

The fundamental premise to make attractive the utilization of a CHP is the contemporarily presence of thermal and electrical loads, with the possible option to sell electricity to the network if appropriate market conditions are verified (e.g. CHP variable cost is more competitive than other available power plants) or regulatory prescriptions are in place (e.g. feed-in tariff, priority of dispatching, etc.). In light of this, it can be said that CHPs are particularly suitable for process industries, where a substantial amount of heat, often in form of steam, and electricity are often required.

The study of cogeneration system has attracted the interest of many researchers all around the world because of the multitude of applications they can have in a wide range of sectors, spanning from oil $\&$ gas industry to residential purposes.

For example, Pagliarini et al. [3] developed an analysis of a tri-generation plant intended for a hospital application in Italy. They performed a dynamic simulation of the system by modelling the hourly behaviour of the plant. They also propose an economic analysis of the system from which it is possible to conclude that the investment is profitable only if the national support is present. Similarly, Armanasco et al. [4] performed a techno-economic analysis to understand which users can take advantage, on the Italian electricity market, of a cogeneration plant aimed to cover at least part of their energy demand. The main outcome from their analysis is that, in the industrial sector, independently of the product category, cogeneration is a viable option form a techno-economic perspective.

Brandoni and Renzi [5], instead, proposed a combination between a micro-CHP and a solar PV panel for building applications. Their aim was to find a criterion to determine the optimal size of the system in terms of primary energy savings and economic performances.

Other authors investigated the interaction between the cogeneration plant and the local electricity market, in order to highlight possible opportunities to operate profitably on the spot market. To this scope Konstantakos et al. [6] developed a model to support energy planning and decisionmaking for CHP investments in an unstable energy market. The model uses, as variables, state subsidies, natural gas and electricity selling price. They proposed different case of studies based on the Greek market and concluded that small fluctuations of natural gas price do not affect the investment to a crucial degree. Streckiene et al. [7] analysed the optimal size of a CHP-plant with thermal store under German spot market conditions. They found that given the economic and 
technical assumptions made, a CHP-plant of $4 \mathrm{MW}$-el with a thermal store participating in the spot market will be the most feasible plant to build. They also performed a sensitivity analysis to show at which extent the optimal solution will vary by changing the key economic assumptions.

Moreover, Smith et al. [8] proposed the utilization of the spark-spread as screening parameter for the utilization of CHP. The proposed indicator has the advantage to be very synthetic and easy to calculate.

Another interesting research area is represented by the application of a CHP within an industrial area, therefore serving more plants, so that the load characteristics, both thermal and electrical, tend to compensate and the operation of the cogeneration plant results more convenient.

To this aim, Buoro et al. [9] analysed a supply network composed by micro-CHP, solar plant and thermal storage facilities. They proposed a multi-criteria optimization model based on linear programming techniques, in order to minimize an objective function which ensures the fulfilment of specific goals. The model allows to obtain different optimal solutions by varying the relative weight of the economic and the environmental objectives. Likewise, Starfelt and Yan [10] examined the possible application of a gas turbine CHP within an industrial park located in China. The study includes performance analysis of the cogeneration plant in terms of thermal efficiency, cost estimation, and greenhouse gas emission. The results show that the gas turbine-based cogeneration system can guarantee a relevant increase of efficiency and a substantial reduction of carbon emissions, if compared with the supply from the national network. On the other hand, as highlighted by Ghadimi et al. [11], an appropriate operational strategy is required to obtain the estimated energy efficiency levels and economic returns. They applied this criterion to the CHP system of a pharmaceutical manufacturing plant.

Thanks to the contemporary generation of electricity and heat, CHP plants allow a better exploitation of the fuel, ensuring a low carbon intensity. For this reason Gibson et al. [12] analysed which kind of CHP plant will be the most convenient if a carbon tax system is introduced in Australia. Similarly, Torchio [13] analysed the possibility to use a CHP in combination with a district heating network in order to reduce carbon emissions and primary energy consumption. He analysed the feasibility of such a plant in Northern Italy by taking into account different configurations.

Other authors analysed the possibility to use renewable fuels, namely biomass and biogas in CHP plants. As for instance, Rodrigues et al. [14] and Pantaleo et al. [15] proposed the idea to use biomass in small scale cogeneration plants. In [14], a small steam Rankine cycle is analysed, whereas in [15] an organic Rankine cycle is considered. On the contrary, Kang et al. [16] evaluated 
the suitability to fuel a small scale combined cycle CHP with biogas. They developed an economic analysis and observed that financial indexes are strongly related to the heat sales.

From the reported literature analysis, it can be noticed that cogeneration is utilized in a variety of sectors, including hospitals [2, 3], small-medium size industrial plants [4, 6, 15], buildings [5, 8], district heating [7, 9, 13], pharmaceutical industry [11], animal feed industry [14], generation of heat and electricity for the market [16].

Different authors also proposed the application of cogeneration facilities in the food processing industry, which offers numerous opportunities for its applications, because its processes normally require the contemporary presence of electricity, heat and also cold. Therefore, they provide the ideal energetic context to evaluate the possible introduction of a CHP.

For this reason, Ruiz Celma et al. [17] proposed a feasibility study of a CHP in an olive processing factory located in Spain. They proposed an economic viability analysis and devoted special attention to energy savings and environmental benefits. They concluded that a significant reduction $(-49 \%)$ of primary energy demand may be achieved. On the contrary, Panno et al. [18] considered the application of a CHP in a pasta factory. They performed a feasibility study by taking into account energy savings and environmental benefits for a plant located in south Italy. According to their analysis, the cogeneration system allows to reduce energy cost and carbon emission. Instead, Tassou et al. [19] proposed the application of a tri-generation system to the food retail industry. They analysed the economics and environmental impacts of the technology compared to conventional systems. Their results indicate that the economic viability of these systems is dependent on the relative cost of natural gas and grid electricity. Also Freschi et al. [20] considered the possible utilization of a tri-generation system. They applied this system to a fruit conservation plant with the aim to minimize carbon emissions and operational costs.

Moreover, Sturm et al. [21] studied the application of a CHP in small scale brewery in UK. They considered different system configurations and concluded that the most effective one, also in relation to government support, is the combination of either, boiler or CHP with an absorption chiller.

The present paper investigates on the possibility to implement a cogeneration system in a large plant for the processing of soft drinks located in the north part of Italy. The aim is to perform a detailed technical and financial analysis of a gas turbine based cogeneration plant. The objective is to evaluate the profitability of this investment and its impact in terms of primary energy consumption with respect to a classical configuration, where electricity is obtained from the network and heat is generated by means of natural gas boilers. Different figure of merits are 
considered to evaluate the thermodynamic performance, namely primary energy saving index (PES) and exergetic efficiency, and the financial return, namely net present value, internal rate of return, pay-back period and profitability index.

As a matter of fact, it is crucial to detect the most appropriate economic indicator to be used when the optimal sizing of the plant is investigated.

In this context, most of the published papers described before present the economic analysis as an "ex-post" validation, with the aim to show if the proposed technology is viable from the financial point of view. A general lack of details about the used approach and assumptions in selecting the economic indexes occurs in most of them.

Table 1 reports a list of the most recent papers on CHP thermo-economic analysis, catalogued according to the economic indicators used. As it is possible to see, the most popular indicators are NPV and pay-back period, even though a clear and rational explanation for this choice is not highlighted; furthermore, only in a few cases a comparison between them is carried out. Moreover, it should be also mentioned that in these analyses limited considerations are dedicated to the evolution of fuel prices, which represents one of the main input to evaluate the profitability of investments in energy efficiency measures.

Starting from the above considerations, the purpose of the present work is to highlight the different conclusions that can be obtained by using different financial indicators. As discussed along this paper, this choice is also strictly related to the global strategy of a company/investor, which represents an important input to take into account for the analysis of a case study.

It is authors' opinion that the comments and considerations reported in the paper are of interest for energy managers and processing plant managers, in order to optimize the energy performances of their facilities.

\section{Analysis of the case of study}

\subsection{Description of the processing facility}

The production facility is active five days per week, operating in two shifts, from 6 in the morning until 22 in the evening, but in periods of maximum demand, typically before Christmas holidays, the plant is run continuously, 24 hours per day.

The facility has a production between 2000 and 70000 bottles per hours, depending on the types of products. It has a surface of $60000 \mathrm{~m}^{2}$ and it is located in the North of Italy. A schematic of the production facility is reported in Figure 1(a), where two different areas can be highlighted:

- the processing area, divided into different cellars and warehouses, in which all processes on the raw materials occur; 
- the post-processing area, which is divided into three places: (i) the empty bottle warehouse, (ii) the bottling area and (iii) the full bottle warehouse.

These two zones are divided by a corridor which allows the communication between the two sections and, on the ceiling of the corridor, the pipelines of the "distribution system" are located. The distribution system delivers to the different locations of the plant all the resources necessary for the production, in particular: products, heating steam and processing steam, as shown in Figure $1(b)$.

All thermal power production systems are placed in the utilities area (Figure 1a) together with the maintenance room with the spare parts warehouse, the hydric and glycol supply systems.

The plant is operated in a "make to stock" logic based on demand forecasts elaborated by the company and a batch production is adopted, in order to optimize the set-up time of the production lines (e.g. the time to change the typology of fillers according to the different formats of bottles related to the specific drink under production).

\subsection{Energy supply and consumption}

The primary energy demands of the considered industrial facility are related to:

- natural gas consumption to fuel the steam generators;

- electric energy consumption of all equipment.

Currently, both electric energy and natural gas are bought from the national distribution grid.

Thermal energy is produced by 4 boilers with a nominal power of about $2.5 \mathrm{MW}$ each. In order to maintain a certain flexibility degree, the system was designed to provide the required thermal power with only two boilers, whereas another one is in stand-by for potential peak productions and the last one is under cyclic maintenance.

Thermal energy is used to produce steam at a pressure of $\sim 3$ bar which is mainly used:

- directly and for water heating during the industrial processes;

- for building heating purposes

The yearly electric energy consumption of the production facility is about $11.5 \mathrm{GWh}$, mainly due to equipment (compressors and pumps), cooling system and heating generation in stand-alone processes. Three primary transformer rooms 15000/380 V connected with the national grid are installed and located in different areas in order to achieve a convenient distribution to all end users. Figure 2(a) shows the monthly electric energy and natural gas consumptions of the production facility between June 2014 and July 2015. Generally, the larger consumption of natural gas occurs during the winter season (in particular, January, February and March) as result of an increased 
production and the building heating requirement. December and August present the lower consumption due to the presence of public holidays in which the production is stopped.

On the other hand, the electric energy consumption shows a lower fluctuation along the year, with a mean monthly value of about $960 \mathrm{MWh}$. The minimum values occur in August, December and April due to the lower working hours in these months.

Figure 2(b) shows the costs related to the energy supply, namely electricity and natural gas, and the monthly production (in litres) for the same period. As it is possible to note, total energy costs are roughly correlated to the level of production and the electricity has the main share. In light of this, it can be assumed that the energy costs are direct production costs (i.e. they proportionally vary with the level of production).

Finally, figure 3(c) reports the monthly consumption indexes for both electric energy (Eq. 1) and natural gas (Eq. 2) in the considered period.

$$
\begin{aligned}
\mathrm{El}_{\text {index }} & =\frac{\text { Electricity consumption }\left[\mathrm{kWh} h_{e}\right]}{\text { Production [litres] }} \\
\mathrm{Gas}_{\text {index }} & =\frac{\text { Gas consumption }[\mathrm{scm}]}{\text { Production [litres] }}
\end{aligned}
$$

The indexes show some interesting features of the production process, which highlight how the production management influences energy consumption. For example, during the month of August it can be noticed that the $\mathrm{El}_{\text {index }}$ is quite above the average.

This is due to the fact that there are two weeks of closure for summer holidays, therefore the level of production is lower if compared to July, but the refrigeration plants are on, in order to store finished and the work in progress products.

Similarly, it can be observed that the specific amount of natural gas consumption is higher during the winter period, because the heating system of the plant is switched on, in order to guarantee comfortable working conditions to the workers.

\section{Design of the cogeneration facility}

\subsection{Thermodynamic analysis}

The analysed industrial process is characterized by both thermal and electrical loads that are almost constant during a typical working day, therefore, cogeneration seems a suitable option to replace the existing system in an efficient way. Thermal and electricity consumptions of the industrial plant remain unchanged and they represent the main input for the design of the new system. 
A CHP system based on the use of a gas turbine is chosen. A typical gas turbine works above 800 ${ }^{\circ} \mathrm{C}$ and the exhausted gases are in $430-540{ }^{\circ} \mathrm{C}$ temperature range, which can be used for the steam generation in substitution of boilers. The schema of the proposed CHP system is reported in Figure 3(a), while the thermodynamic cycles of reference are shown in Fig. 3(b).

The part of electricity power not covered by the CHP is bought from the network and the heat generation is calculated according to the CHP parameters. Integration is provided by the existing boilers if the new system is not able to supply all the thermal power required by the user.

The mathematical model of the CHP system consists of a set of energy balance equations which permits to identify each thermodynamic point along the circuit. Each process is considered steadystate, while pressure drops, heat losses through pipe lines, potential and kinetic energies of the flowing fluid are considered negligible.

\subsubsection{Gas turbine cycle (GT)}

The external air, at the atmospheric pressure, is compressed to the desired pressure by means of a compressor and then it passes through a pre-heater to recover part of the exhausted gas heat and, consequently, to reduce the amount of energy required in the combustion chamber. The fuel (natural gas) is injected directly in the combustion chamber and, then, the resulting gas flows through the turbine generating mechanical power. Finally, the exhausted gas passes through the air pre-heater and enters into the heat recovery steam generator (HRSG). The following governing equations can be applied:

$$
\begin{aligned}
& P_{\text {comp }}=\dot{m}_{a}\left(h_{2}-h_{1}\right) \\
& Q_{c c}=\dot{m}_{\text {fuel }} L H V_{\text {fuel }}=\left(\dot{m}_{g} h_{4}-\dot{m}_{a} h_{3}\right) / \eta_{c c} \\
& \dot{m}_{g}=\dot{m}_{\text {fuel }}+\dot{m}_{a} \\
& P_{\text {turb }}=\dot{m}_{g}\left(h_{5}-h_{4}\right) \\
& Q_{R E G}=\dot{m}_{a}\left(h_{3}-h_{2}\right)=\dot{m}_{g}\left(h_{5}-h_{6}\right) \\
& Q_{E V A}=\dot{m}_{g}\left(h_{6}-h_{7}\right) \\
& Q_{E C O}=\dot{m}_{g}\left(h_{7}-h_{8}\right) \\
& Q_{H R S G}=Q_{E V A}+Q_{E C O}
\end{aligned}
$$

The net electric energy produced by the turbine and the efficiency of the gas turbine cycle can be calculated as follows:

$$
\begin{aligned}
& P_{n e t}=\left(P_{\text {turb }}-P_{\text {comp }}\right) \cdot \boldsymbol{1}_{\text {mech }} \cdot \boldsymbol{1}_{e l} \\
& r_{G T}=P_{\text {net }} / Q_{c c}
\end{aligned}
$$


The main assumptions and constraints for the thermodynamic calculations are reported in table 2. The mass flow rate of gas is determined from Eq. (6) by imposing the power of the turbine. The rationale behind this choice is represented by the fact that one of the most accurate data generally available in the design of a CHP is the necessary electrical output, which is directly linked to the mechanical power of the turbine.

\subsubsection{Steam cycle (ST)}

In order to maximize the usage of the fuel, a steam cycle is adopted to generate thermal energy for the user by means of a heat recovery steam generator (HRSG). According to the industrial process requirements, heat has to be supplied at a nominal temperature of $130^{\circ} \mathrm{C}$ with a lower grade of fluctuation. Therefore, assuming a margin of $10^{\circ} \mathrm{C}$, the maximum temperature of the ST cycle is set at $140^{\circ} \mathrm{C}$ (point 13-14) with a correspondent upper pressure of 3.6 bar. The thermodynamic cycle is modelled considering the following assumptions:

- The fluid entering into the pump (point 11) is assumed to be saturated liquid at the correspondent condenser pressure (quality $=0$ ).

- An isentropic efficiency $\eta_{P}$ equal to 0.75 has been adopted for the circulation pump.

- It is assumed a quality value of the fluid at the HRSG outlet point (14) equal to 0.94 (no overheating is provided).

- The temperature difference between the points 13 and 7 (Pinch Point, see Eq. 13) is an input parameter of the proposed model and it is assumed equal to $15^{\circ} \mathrm{C}$.

$$
T_{13}=T_{7} \dashv \mathrm{PINCH}
$$

The following governing equations can be applied:

$$
\begin{aligned}
& P_{\text {pump }}=\frac{\dot{m}_{w}\left(h_{12, i}-h_{11}\right)}{\eta_{p}}=\dot{m}_{w}\left(h_{12}-h_{11}\right) \\
& Q_{E C O}=\dot{m}_{w}\left(h_{13}-h_{12}\right) \\
& Q_{E V A}=\dot{m}_{w}\left(h_{14}-h_{13}\right) \\
& Q_{U S E R}=\dot{m}_{w}\left(h_{16}-h_{11}\right) \\
& Q_{\text {COND }}=\dot{m}_{w}\left(h_{17}-h_{11}\right)
\end{aligned}
$$

\subsection{Exergy analysis}

Over the last few years, the exergy analysis has become a useful tool for the design and the optimization of energy system. Exergy represents the available energy (or, in other words, the useful work potential) of a system at the specified thermodynamic state and permits to take into 
account the "quality" of the energy fluxes of the system. The main exergy characteristic is that it can be destroyed along the process because of the entropy generation due to cycle irreversibility; as shown in Eq. 19 the exergy destroyed is always a positive quantity for any real process and, at least, it becomes zero for reversible processes.

$$
I=T_{0} S_{g e n} \geq 0
$$

Generally, it is possible to define the exergy at a certain thermodynamic state $i$ as shown in Eq. 20, where the index 0 indicates the chosen reference state (or dead state [22]). In the present work, the ambient conditions (temperature and pressure) are assumed as reference state for the exergy calculations.

$$
E_{i}=\dot{m}\left[\left(h_{i}-h_{0}\right)-T_{0}\left(s_{i}-s_{0}\right)\right]
$$

An exergy balance equation for a steady-state system can be written as follows:

$$
\sum_{j}\left(1-\frac{T_{0}}{T_{j}}\right) Q_{j}-W+\sum_{x}\left(\dot{m}_{i, x} E_{i, x}\right)-\sum_{y}\left(\dot{m}_{o, y} E_{o, y}\right)-I=0
$$

where the suffixes $i$ and $o$ mean "inlet" and "outlet", $W$ is the work rate of the control volume, $Q_{j}$ is the heat transfer rate at the temperature $T_{j}$ through the boundary and $I$ represents the total exergy destroyed. Therefore, it is possible to define a second-law efficiency (or exergy efficiency), as shown in Eq. 22:

$$
\eta_{e x}=\frac{\text { Exergyused }}{\text { Exergysupplied }}=1-\frac{\text { Exergydestroyed }- \text { Exergylost }}{\text { Exergysupplied }}
$$

Where "exergy lost" represents the sum of the exergy flows from the stack and the condenser towards the environment.

\subsection{Estimation of investment costs}

Assuming that the new system will be integrated with the existing one, the overall cost of the investment (CAPEX) required to build up the CHP system is calculated considering the costs of the GT components and of the HRSG. In the present work, these costs are calculated as function of the thermodynamic parameters according with the following equations [23]:

Compressor:

$$
P E C_{\text {comp }}=\left(\frac{C_{11} \dot{m}_{a}}{C_{12}-\eta_{\text {comp }}}\right) \cdot\left(\frac{p_{2}}{p_{1}}\right) \ln \left(\frac{p_{2}}{p_{1}}\right)
$$

Combustion chamber: $\quad P E C_{c c}=\left(\frac{C_{21} \dot{m}_{a}}{C_{12}-\frac{p_{4}}{p_{3}}}\right) \cdot\left[1+\exp \left(C_{23} T_{4}-C_{24}\right)\right]$ 
Turbine:

$$
P E C_{\text {turb }}=\left(\frac{C_{31} \dot{m}_{a}}{C_{32}-\eta_{\text {turb }}}\right) \cdot \ln \left(\frac{p_{4}}{p_{5}}\right) \cdot\left[1+\exp \left(C_{33} T_{4}-C_{34}\right)\right]
$$

Air pre-heater: $\quad P E C_{a p h}=C_{41}\left(\frac{\dot{m}_{g}\left(h_{5}-h_{6}\right)}{U \Delta T_{m l, a p h}}\right)^{0.6}$

HRSG:

$$
P E C_{H R S G}=C_{51}\left[\left(\frac{Q_{E C O}}{\Delta T_{m l, E C O}}\right)^{0.8}+\left(\frac{Q_{E V A}}{\Delta T_{m l, E V A}}\right)^{0.8}\right]+C_{52} \dot{m}_{w}+C_{53} \dot{m}_{g}^{1.2}
$$

The values of the constants appearing in Eq. 23-27 are shown in Table 3 [23]. Finally, the total investment cost (in 1994 \$) can be calculated as shown in Eq. 28.

$$
I N V_{1994, \$}=P E C_{\text {comp }} \dashv P E C_{c c} \dashv P E C_{\text {turb }} \dashv P E C_{a p h} \dashv P E C_{H R S G}
$$

In order to obtain the current estimation of the investment in $€$, the value obtained from Eq. 28 has to be compounded to the current year (2015), taking into account the mean inflation rate $(2.3 \%)$ and foreign exchange ratio (1.12 $€ / \$)$ of the period 1994-2015. Thus, the nominal CAPEX in $€$ can be calculated according to Eq. 29, where $y$ is the number of years from 1994 to 2015 ( $\mathrm{y}=21)$.

$$
I N V=1.12 \cdot I N V_{1994, \$} \cdot(1+i)^{y}
$$

\subsection{Economic analysis}

In order to evaluate if the cogeneration system is convenient, it is necessary to estimate its operating costs and possible revenues (e.g. selling of electricity to national network) sources and to compare them with the existing energy supply costs, namely payments for electricity and natural gas bills.

The yearly variable cost (CV) of the CHP can be estimated in the following way:

$$
C V_{i}=C_{\text {Fuel }, i}+C_{C a r b o n, i}+\operatorname{VOM}_{i}
$$

Where $\mathrm{C}_{\text {Fuel }}$ is the variable cost of the fuel, natural gas in the present case, $\mathrm{C}_{\text {Carbon }}$ is the $\mathrm{CO}_{2}$ cost, which has to be paid if the nominal thermal power of the plant is lower than $20 \mathrm{MWt}$ [24], and VOM is the variable operating and maintenance cost.

The fuel variable cost can be calculated as:

$$
C_{\text {Fuel }, i}=\frac{C_{N G, i}}{\eta_{G T}}
$$

where $\mathrm{C}_{\mathrm{NG}, \mathrm{i}}$ is the natural gas cost in year "i”, expressed in €/MWht.

The carbon cost, if applicable, can be expressed as:

$C_{\text {Carbon }, i}=\frac{C_{\text {Carbon, } i} \cdot E F}{\eta_{G T}}$ 
where $\mathrm{C}_{\text {Carbon, } \mathrm{i}}$ is the carbon cost in year " $\mathrm{i}$ ”, expressed in $€ / \mathrm{t}$, and $\mathrm{EF}$ is the emission factor, expressed in $\mathrm{t} / \mathrm{MWht}$. Finally, the $\mathrm{VOM}_{\mathrm{i}}$ cost is directly expressed in $€ / \mathrm{MWhe}$.

By multiplying the $\mathrm{CV}_{\mathrm{i}}$ of the $\mathrm{CHP}$ for the amount of electrical generation, its yearly operating cost is determined.

The total operating cost of the cogeneration configuration can be written as:

$C V_{C H P, i}=C V_{i} \dashv Q_{\mathrm{int}, i} \dashv E_{\mathrm{int}, i}-E_{\text {sell }, i}$

Where $\mathrm{Q}_{\mathrm{int}, \mathrm{i}}$ and $\mathrm{E}_{\mathrm{int}, \mathrm{i}}$ are the possible costs in year "i”" associated with thermal power and electricity integrations obtained from the existing boilers and electrical network, if the CHP is not able to cover the whole demand of heat and electricity. Whereas, $\mathrm{E}_{\text {sell,i }}$ is the possible revenues from selling the extra generation of electricity in year "i".

In order to determine the potential yearly saving, $\mathrm{CV}_{\mathrm{CHP}, \mathrm{i}}$ must be compared with the current situations, where heat is supplied by means of natural gas boilers and electricity is bought directly from the network, therefore:

$C F_{i}=E C_{e x, i}-C V_{C H P, i}$

Where $\mathrm{CF}_{\mathrm{i}}$ is the yearly money saving, namely the yearly cash flow, and $\mathrm{EC}_{\mathrm{ex}, \mathrm{i}}$ is the yearly energy cost in the existing situation, namely the sum of natural gas and electricity bills.

If $\mathrm{CF}_{\mathrm{i}}$ is greater than 0 , than the $\mathrm{CHP}$ configurations guarantees lower operating costs, but this is not enough to state that the investment in the CHP is convenient.

In order to assess the convenience of the CHP systems, different indicators are taken into account: net present value (NPV), internal rate of return (IRR), profitability index (PI) and pay-back period (PB) are calculated. In particular, the NPV is defined as follows:

$\mathrm{NPV}=-I N V \dashv \mathrm{DCF}$

where DCF is the discounted cash flow during the operating life of the CHP, which can be calculated according to Eq. 36:

$\mathrm{DCF}=\sum_{i=1}^{n} \frac{C F_{i}}{(1+r)^{i}}$

where $n$ is the operating life of the plant and $r$ is the discount rate. In general $r$ value between $8 \%$ $12 \%$ is considered adequate for such kind of investments on the Italian market.

The IRR has a definition similar to that of the NPV and it consists in the calculation of " $r$ ", when NPV is equal to 0 :

$\sum_{t=1}^{n} \frac{C F_{i}}{(1+r)^{i}}=I N V$

Instead the PI determines the ration between the DCF and the investment cost: 


$$
P I=\frac{D C F}{I N V}
$$

Finally, the pay-back period can be defined as the time required to recover the investment cost. The equation has the same form of Eq. (37), but the unknown variable is the time "t".

\subsection{Regulatory framework}

EU legislation considers cogeneration as one of the main milestones of its energy policy, in fact special measures to support the diffusion of CHP have been emanated since 2004, with the introduction of the 2004/08/EC directive, also known as "CHP Directive". This directive had the objective to propose a standard methodology to calculate the primary energy savings obtained by using cogeneration, which gave rights to obtain incentives. Then the directive was updated with the emanation of the "Energy efficiency directive" [1].

The overall aim of legislative interventions is to promote efficient cogeneration by implementing different support schemes. On the other hand there are some concerns on the effectiveness of these mechanisms, in fact Moya [25] observes that there is no evidence of a relationship between the economic advantage offered by support measures and the deployment of cogeneration. According to EU directives, the global efficiency of the CHP system can be measured by calculating the primary energy saving index (PES), which can be determined as follows:

$$
P E S=1-\frac{Q_{c c}}{\frac{P_{n e t}}{\eta_{e l, r e f}}+\frac{Q_{U S E R}}{\eta_{t, r e f}}}
$$

where $\eta_{\mathrm{el}, \mathrm{ref}}$ is a reference electric efficiency (assumed equal to 0.522 [4]), which corresponds to the most efficient thermo-electrical conversion technology currently available accounting for a grid loss correction term. Similarly, $\eta_{t, r e f}$ are the reference thermal efficiency (assumed equal to 0.90 [24]), corresponding to the best technology for boilers currently available.

For CHP with electric power greater than $1 \mathrm{MW}$, if PES is greater than $10 \%$, the plant is eligible for incentives. As for Italy, the most important support measure consists in fiscal discount on the price of fuel. In the present paper the incentives will not be considered in the investment valuations and they can be seen as possible "upsides". PES will be calculated in order to estimate the possible increase of efficiency in the generation of heat and power of the considered cogeneration plant with respect to the country average.

\subsection{Market context}

The considered cogeneration plant is fuelled with natural gas and it supplies the factory with heat and power, but it potentially has the possibility to sell electricity to the network if there is an excess 
of generation. To estimate the economic performance of the CHP, it is necessary to have a future outlook on the evolution of natural gas and power prices.

As reported in [26], European natural gas sector experienced radical changes moving from an "oil linked" towards a "hub based" (or "spot") price system. On the other hand, as detailed discussed in [27], it is expected that most of the companies not involved in the energy business prefers to sign long term agreements with suppliers, rather than to invest resources to develop a knowhow to operate on the gas market. In light of this, the evolution of natural gas price on the border, namely import price, can be obtained in the following way:

$P_{\text {imp }}=0.768 \dashv 0.099 \cdot P_{\text {oil }}$

Where $\mathrm{P}_{\mathrm{oil}}$ is taken from DECC estimation [28].

The evolution of the final price is obtained by applying the percentage year by year price calculated by using Eq. (40) to the price actually paid by the company in the period of observation (e.g. $06 / 2014$ - 05/2015). In other words, it is assumed that the incidence of taxes and commercial fees is taken constant and there is a percentage variation year by year only due to the price of commodity (i.e. the import price).

Similarly, it is necessary to develop an outlook for the evolution of power prices, in order to estimate the value of the possible amount of the electricity sold. The evolution of prices from 2016 up to 2022 is taken from [29], whereas for the following years the trend is extrapolated. As largely discussed in [29], the marginal technology on the Italian power market is represented by Combined Cycle Gas Turbine (CCGT), therefore the evolution of power prices will be closely linked to the gas price evolution. This makes the investment in gas based CHPs very resilient to changes in natural gas prices, because electricity prices will change correspondingly.

Similarly to the extrapolation of gas price, the percentage variation of the market electricity price is applied to the price actually paid by the company to buy electricity, whereas the selling price is set equal to the market price.

For both the price, i.e. electricity and gas, two scenarios are considered; an "average" scenario, where a regular evolution of the market is considered and a "high" scenario where tighter market conditions are taken into account. According to the aforementioned assumptions, the evolutions of natural gas and power prices are reported in Figure 4.

\section{Results and discussion}

According to the aforementioned technical, financial and market assumptions an evaluation is performed in order to assess the feasibility of the CHP and to determine the optimal electricity power which maximises the effectiveness of the investment according to different indicators. To 
this aim, a parametric analysis is developed by varying $\mathrm{P}_{\text {turb }}$ and $\beta$ in a range such to have an electrical output between $\sim 20 \%$ and $\sim 110 \%$ of the monthly average plant demand, which is supposed to be adequate to find the optimum point as it will be shown in the following. The average air temperature of the location where the CHP has to be installed varies from $\sim 5 \quad \mathrm{C}$ up to $\sim 30 \quad \mathrm{C}$ all along the year and the average yearly temperature can be estimated in $12.9 \mathrm{C}$. This parameter is very important and it has a relevant impact on the performance of the CHP, affecting the average monthly efficiencies of the plant, as shown in Fig. 5.

Fig. 5(a) reports some key performance indicators determined by using the average temperature, whereas Fig. 5(b) shows the behaviour of the exergy efficiency as a function of the external air temperature. From the analysis of Fig. 5(a), it is detected that at the increase of the GT pressure ratio $(\beta)$, the PES index increases and it always has a value greater than $10 \%$, which means that the CHP can be considered as a high efficient plant, eligible for incentives. This trend can be explained with the increase of the efficiency, if compared with traditional boilers, of the heat generation by means of the utilization of the exhausted gas of the gas turbine.

On the contrary, the exergy efficiency tends to decrease at the increase of $\beta$. This tendency can be explained with the fact that as $\beta$ increases, by keeping constant the turbine power, there is a decrease of the input exergy in the system, mainly represented by the fuel in the combustion chamber of the GT cycle, but, at the same time, there is also a decrease of the useful exergy of the system and this share is prevalent with respect to the previous one.

This also highlights the motivation for the increase of PES, which can be seen as a measure of fuel exploitation. In fact, at the increase of $\beta$, a lower mass flow rate of fuel is necessary to obtain the same electrical and thermal power, i.e. a better utilization of the fuel is accomplished.

Fig. 5(b) shows how the exergy efficiency varies during the months according to the environmental temperatures. As the external temperature growths, exergy efficiency tends to decrease because there is a concurrent decrease of the exergy input and of the useful exergy of the system, which prevails determining a decrease of the exergy efficiency.

In light of the efficiency variations highlighted in Fig. 5(b), the profitability indexes are calculated on a monthly basis and then summed, so that the efficiency variations can be taken into account. Figure 6 reports the investment costs for the $\mathrm{CHP}$ as a function of three different pressure ratios (i.e. the ratio between the outlet and inlet pressures at the compressor), namely 6, 8, 10, typical for such a kind of devices, and the generated electricity power. This cost is estimated according to Eq. (29) and it depends on the thermodynamic parameters of the CHP. In particular, the investment cost increases at the increase of the dimensions of the system, i.e. higher electricity power, and to the performance of the system, i.e. higher pressure ratio " $\beta$ " guarantees a higher CHP PES. In general, 
the investment cost does not provide any information on the convenience of the system, but it is fundamental to evaluate the profitability of the investment.

Figure 7 shows the trend of the four investment indexes taken into account in the present paper for the "average" electricity and gas prices scenarios.

In particular, Fig. 7(a) presents the NPV curves, which highlights an interesting pattern. First of all, it can be noticed that at the increase of " $\beta$ " from 6 to 10, there is a reduction of the NPV. This means that the increase of the investment cost due to better performances is not justified by the hypothesised market conditions, therefore the optimal design condition to maximize the profitability of the investment is to set $\beta$ equal to 6. Moreover, the NPV trend highlights an absolute maximum point, which is approximately obtained for electricity power of 2.8-2.9 MW for the values of $\beta$. This allows to set a second important design parameter, namely the electricity power of the CHP. Figure 7(b) reports the trend of the IRR, which confirms that $\beta$ equal to 6 represents the best design condition to maximize the profitability of the investment. Similarly to the NPV, also the IRR shows an absolute maximum, which is reached for electricity power between 2.0-2.2 MW for $\beta=6,1.8-2.0$ MW for $\beta=8$ and 1.6-1.8 MW for $\beta=10$.

If the IRR criterion is considered the optimal electricity power design is lower with respect to the values determined according to the NPV. This difference is due to the fact that the IRR criterion is more favourable for investments with a smaller initial investment cost, as in case of smaller nominal power, because it is easier to obtain a higher return. This is true in relative terms, i.e. in terms of rate of return, but in absolute terms, i.e. money earned, it is not true. Therefore, if the scope is to maximize the cash flow the NPV rule should be followed, instead if the object is to maximize the rate of return of the invested capital, IRR rule should be considered Another important consideration that can be done by observing Fig. 7(b) is that the IRR is always above $20 \%$, which means that the minimum value of "r" (see Eq. 36) to set the NPV of the investment equal to 0 should above $20 \%$. In the present study, a value of "r" equal to $8 \%$ is considered, this means that the risk that investment would result unprofitable is quite low, because the difference between the assumed " $r$ " and IRR is quite relevant.

Figure 7(c) presents the trend of the profitability index. This indicator can be considered as measure of the efficiency of the investment, because it gives an idea about the ratio between money earned and the investment. It can be effectively used to rank different alternatives. The plot highlights the same trend of $\beta$ as in the case of NPV and IRR, whereas the electrical power which maximize the PI are the following: $2.0-2.2 \mathrm{MW}$ for $\beta=6,1.8-2.0 \mathrm{MW}$ for $\beta=8$ and 1.6-1.8 MW for $\beta=10$. The values are similar to those determined in the case of IRR, because the meaning of the index is quite similar. 
Figure 7(d) reports the trend of the pay-back period. It is important to highlight that if the analysis is based on the pay-back period what happens after the recovery of the investment is not taken into account, whereas all the other considered indexes analysis include all the operating life of the CHP plant. The same consideration as in the previous cases can be done about $\beta$, whereas in terms of optimal electrical power the following values are obtained: 2.2-2.3 MW for $\beta=6,1.9-2.0 \mathrm{MW}$ for $\beta=8,1.6-1.7 \mathrm{MW}$ for $\beta=10$.

An interesting feature highlighted in Fig. 7, independently from the chosen indicator, is represented by the fact that, after a certain value of the electricity power of the CHP, a relevant deterioration of the investment indexes is detected. This is due to the fact that when nominal power increases after a certain value, there is an oversupply of heat which is wasted in the environment and causes a destruction of value.

The analysis of the investment indexes has shown that, according to the specific indicator taken into account, different optimal design parameters are obtained. This means that the technical design of the CHP is closely linked to the operational strategy of the company. For example, if the strategy is focused on the minimization of risks for the investors, than it is aimed at the recovering of the invested capital as soon as possible, therefore it is necessary to minimize the pay-back period. On the contrary, if the strategy aims at maximizing the absolute value of the investments, than the NPV should be maximized; similar conclusions can be done also for IRR and PI.

All this highlights how the decisions, even those that may appear as "merely technical", should be framed within the global strategy of a company. In order to generalise the presented results, Table 4 reports some common rules which allow to choose the most suitable financial indicator according to the kind of analysis to perform.

The utilization of the CHP system modifies the sources of supply for thermal and electrical energy, as well as the consumption of natural gas. Figure 8(a) shows that at the increase of the electrical power of the CHP, the supply from the market decreases and for an electrical power of $\sim 3 \mathrm{MW}$ the share bought on the market is approximately 0 , whereas there is the presence of a quota sold to the market. Fig. 8(b) offers a picture in terms of gas consumption, which is mainly due to the CHP as the electrical power increase and only a residual part is utilized in the boiler to cover the demand peaks.

Similarly, Fig. 9 shows how the monthly electrical and thermal demand is covered. The optimal case in terms of NPV is considered, namely $\beta=6$ and $P_{e l}=2.9$ MW. Fig. 9(a) reports that this system is substantially able to cover the monthly electrical demand with the only exception of the month of August, where integration from the electrical network is needed. Likewise, Fig. 9(b) presents the monthly balance in terms of thermal energy and it can be detected that during the winter months 
integration from the boiler is necessary, because the CHP is unable to cover the thermal demand due to the production processes and winter heating.

Finally, Table 3 reports the profitability indicators for the high price scenarios for electricity and gas prices. It can be detected that the "high" scenario determines an improvement of the profitability indicators. This phenomenon is due to the fact that natural gas is converted in useful energy, both electrical and thermal, with higher efficiency with respect to traditional system, therefore the wastes are reduced. In a scenario with high energy prices, the value of energy harvesting is much higher, therefore the profitability of the investment is higher. Therefore, it can be stated that, in general, the higher is the energy price, the more convenient is an investment in an energy harvesting technology, such as CHP.

\section{Conclusions}

The present study reports a complete thermodynamic and economic analysis of a CHP facility to be installed in a large plant for the processing of soft drinks located in Northern Italy. The main aim was to evaluate the system profitability with respect to the current configuration in which electricity is bought from the national grid, while thermal energy is generated by natural gas boilers. Several performance indexes are considered, taking into account both thermodynamic (PES, and the exergy efficiency) and economic (namely, NPV, IRR, PBP and Profitability Index) points of view. In particular, a complete analysis of a gas turbine CHP has been described in order to identify its optimal dimensions with respect to different profitability indicators. The main results can be summarized as follows:

- The PES index shows always values greater than $10 \%$ (therefore, the CHP could be eligible for incentives since it can be considered as a high efficient plant) and it increases with the increase of the GT pressure ratio $(\beta)$.

- The exergy efficiency tends to decrease at the increase of $\beta$, since the reduction of useful exergy is higher than the decrease of the exergy in input to the system. Moreover, as the external temperature growths, exergy efficiency tends to decrease, since the temperature of the dead state increases.

The investment cost for the CHP system increases at the increase of the system dimension and performances, as the complexity of the plant is higher. To evaluate the economic profitability of the investment, the trends of the main economic indexes were analysed. The obtained results are summarized as follows: 
- Greater cost to achieve better performances (e.g. increasing the pressure ratio) is not justified by the hypothesised market conditions.

- Independently from the chosen indicator, a relevant deterioration of the investment indexes is detected after a certain value of the electricity power of the CHP, due to an oversupply of heat causing an increased amount of wasted energy.

- Different optimum configurations are detected according to the chosen indicator: if the NPV is selected, the optimum corresponds to an installed turbine power (electrical) of 2.8-2.9 $\mathrm{MW}_{\mathrm{e}}$, whereas, values between 2.0-2.2 $\mathrm{MW}_{\mathrm{e}}$ can be obtained with an IRR maximization approach. The main general conclusion is that the financial strategy of the company has a direct impact on the optimal power of the CHP to be installed in the production facility.

Finally, the analysis demonstrates that the CHP is resilient to the increase of energy prices, since better investment indicators were obtained in case of higher prices scenario.

\section{References}

[1] Energy Efficiency Directive 2012/27/EU. Official Journal of the European Union 2012b

[2] U. Çakir, K. Çomakli, F. Yüksel. The role of cogeneration systems in sustainability of energy. Energy Conversion and Management 63 (2012) 196-202

[3] G. Pagliarini, C. Corradi, S. Rainieri. Hospital CHCP system optimization assisted by TRNSYS building energy simulation tool. Applied Thermal Engineering 44 (2012) 150-158

[4] F. Armanasco, L.P.M. Colombo, A. Lucchini, A. Rossetti. Techno-economic evaluation of commercial cogeneration plants for small and medium size companies in the Italian industrial and service sector. Applied Thermal Engineering 48 (2012) 402-413

[5] C. Brandoni, M. Renzi. Optimal sizing of hybrid solar micro-CHP systems for the household sector. Applied Thermal Engineering 75 (2015) 896-907

[6] V. Konstantakos, P.A. Pilavachi, A. Polyzakis, C. Theofylaktos. A decision support model for combined heat and power economic evaluation. Applied Thermal Engineering 42 (2012) 129-135 [7] G. Streckiene, V. Martinaitis, A.N. Andersen, J. Katz. Feasibility of CHP-plants with thermal stores in the German spot market. Applied Energy 86 (2009) 2308-2316

[8] A.D. Smith, N. Fumo, P.J. Mago. Spark spread - A screening parameter for combined heating and power systems. Applied Energy 88 (2011) 1494-1499

[9] D. Buoro, M. Casisi, A. De Nardi, P. Pinamonti, M. Reini. Multicriteria optimization of a distributed energy supply system for an industrial area. Energy 58 (2013) 128-137

[10] F. Starfelt, J. Yan. Case study of energy systems with gas turbine cogeneration technology for an eco-industrial park. International Journal of Energy Research 32 (2008) 1128-1135 
[11] P. Ghadimi, S. Kara, B. Kornfeld. The optimal selection of on-site CHP systems through integrated sizing and operational strategy. Applied Energy 126 (2014) 38-46

[12] C.A. Gibson, M.A. Meybodi, M. Behnia. Optimisation and selection of a steam turbine for a large scale industrial CHP (combined heat and power) system under Australia's carbon price. Energy 61 (2013) 291-307

[13] M.F. Torchio. Comparison of district heating CHP and distributed generation CHP with energy, environmental and economic criteria for Northern Italy. Energy Conversion and Management 92 (2015) 114-128

[14] M.L. de Macedo Rodrigues, F.R. Ponce Arrieta, J.R. Sodré. Small scale biomass CHP plant: An assessment for an animal feed industry. Applied Thermal Engineering 59 (2013) 174-181 [15] A.M. Pantaleo, P. Ciliberti, S. Camporeale, N. Shah. Thermo-economic assessment of small scale biomass CHP: steam turbines vs ORC in different energy demand segments. Energy Procedia 75 (2015) $1609-1617$

[16] J.Y. Kang, D.W. Kang, T.S. Kim, K.B. Hur. Comparative economic analysis of gas turbinebased power generation and combined heat and power systems using biogas fuel. Energy 67 (2014) 309-318

[17] A. Ruiz Celma, F. Cuadros Blazquez, F. Lopez-Rodriguez. Feasibility analysis of CHP in an olive processing industry. Journal of Cleaner Production 42 (2013) 52-57

[18] D. Panno, A. Messineo, A. Dispenza. Cogeneration plant in a pasta factory: Energy saving and environmental benefit. Energy 32 (2007) 746-754

[19] S.A. Tassou, I. Chaer, N. Sugiartha, Y.T. Ge, D. Marriott. Application of tri-generation systems to the food retail industry. Energy Conversion and Management 48 (2007) 2988-2995

[20] F. Freschi, L. Giaccone, P. Lazzeroni, M. Repetto. Economic and environmental analysis of a trigeneration system for food-industry: A case study. Applied Energy 107 (2013) 157-172 [21] B. Sturm, M. Butcher, Y. Wang, Y. Huang, T. Roskilly. The feasibility of the sustainable energy supply from bio wastes for a small scale brewery - A case study. Applied Thermal Engineering 39 (2012) 45-52

[22] Çengel YA, Boles MA. Thermodynamics - An Engineering Approach. 5th ed. McGraw-Hill, New York; 2006.

[23] A. Bejan, G. Tsatsaronis, M. Moran. Thermal design optimization. John Wiley \& Sons 1995.

[24] Italian Ministry of the Environment. http://www.minambiente.it/pagina/il-campo-diapplicazione-del-sistema-ets-il-iii-periodo-2013-2020-gli-impianti-stazionari [25] J. A. Moya. Impact of support schemes and barriers in Europe on the evolution of cogeneration. Energy Policy 60 (2013) 345-355 
[26] V. Bianco, F. Scarpa, L.A. Tagliafico. Current situation and future perspectives of European natural gas sector. Frontiers in Energy 9 (2015) 1-6

[27] V. Bianco, F. Scarpa, L.A. Tagliafico. Scenario analysis of nonresidential natural gas consumption in Italy. Applied Energy 113 (2014) 392-403

[28] DECC. UK Department of Energy and Climate Changes.

[29] V. Bianco, F. Scarpa, L.A. Tagliafico. Long term outlook of primary energy consumption of the Italian thermoelectric sector: Impact of fuel and carbon prices. Energy 87 (2015) 153-164

\section{Figure Captions}


Figure 1. Schematic of the processing facility: overview of the production plant (a) and detail of the distribution system (b)

Figure 2. Monthly energy needs during the monitoring period: (a) electricity and gas consumption;

(b) energy cost in relation to the production; (c) specific energy consumption

Figure 3. CHP plant: (a) schematic of the system; (b) qualitative thermodynamic cycles of both gas turbine and steam cycles

Figure 4. (a) Evolution of prices selling and buying electricity price; (b) natural gas price

Figure 5. (a) Efficiency indicators of the CHP; (b) monthly profile of exergy efficiency

Figure 6. Investment costs as a function of the electrical power and the compression ratio

Figure 7. Profitability indicators as function of the electrical power and compression ratio: (a) NPV,

(b) IRR, (c) Profitability Index, (d) Pay-back Period

Figure 8. Energy supply for the CHP solution as function of the electric power: (a) electricity

balance, (b) natural gas consumption

Figure 9. Monthly electricity (a) and thermal energy (b) balances

\section{Tables}


Table 1. Main financial indicators utilized in the feasibility analysis of CHPs.

\begin{tabular}{ll}
\hline Considered Indicator & References \\
\hline Net Present Value & {$[4],[6],[7],[11],[12],[13],[14],[15],[16],[17],[18]$} \\
\hline Internal Rate of Return & {$[4],[15],[16],[17]$} \\
\hline Pay Back Period & {$[3],[4],[7],[8],[9],[12],[14],[15],[16],[17],[18],[19],[20],[21]$} \\
\hline Profitability Index & {$[17]$} \\
\hline Return on Investment & {$[4]$} \\
\hline
\end{tabular}

Table 2. Main hypothesis for the analysis of the GT cycle

\begin{tabular}{|c|c|c|}
\hline$\beta$ & $6 \leq \beta \leq 10$ & 0.915 \\
\hline $\mathrm{T}_{4}$ & $1000 \mathrm{C}$ & 0.97 \\
\hline $\mathrm{T}_{8}$ & $\geq 120 \quad \mathrm{C}$ & 0.99 \\
\hline$\eta_{\mathrm{c}}$ & 18 & 0.95 \\
\hline$\eta_{\mathrm{rg}}$ & $\mathrm{P}_{\text {turb }}$ & $1.4 \leq \mathrm{P}_{\text {turb }} \leq 8.4 \mathrm{MW}$ \\
\hline
\end{tabular}

Table 3. Constants used in Eq. 23-27 for the purchase cost of the components [23] (in 1994 USD).

\begin{tabular}{lcccc}
\hline Component & Constants & \multicolumn{1}{l}{ Value } & Constant & \multicolumn{1}{l}{ Value } \\
\hline Compressor & $\mathrm{C} 11$ & $71.10 \$ /(\mathrm{kg} / \mathrm{s})$ & $\mathrm{C} 12$ & 0.9 \\
\hline Combustion chamber & $\mathrm{C} 21$ & $46.08 \$ /(\mathrm{kg} / \mathrm{s})$ & $\mathrm{C} 22$ & 0.995 \\
\cline { 2 - 5 } & $\mathrm{C} 23$ & $0.018 \mathrm{~K}^{-1}$ & $\mathrm{C} 24$ & 26.4 \\
\hline Gas turbine & $\mathrm{C} 31$ & $479.34 \$ /(\mathrm{kg} / \mathrm{s})$ & $\mathrm{C} 32$ & 0.92 \\
\cline { 2 - 4 } & $\mathrm{C} 33$ & $0.036 \mathrm{~K}^{-1}$ & $\mathrm{C} 34$ & 54.4 \\
\hline Air pre-heater & $\mathrm{C} 41$ & $4122 \$ /\left(\mathrm{m}^{1.2}\right)$ & $\mathrm{U}$ & $18 \mathrm{~W} /\left(\mathrm{m}^{2} \mathrm{~K}\right)$ \\
\hline HRSG & $\mathrm{C} 51$ & $6570 \$ /(\mathrm{kW} / \mathrm{K})$ & $\mathrm{C} 52$ & 21276 \\
\cline { 2 - 3 } & $\mathrm{C} 53$ & $1184.4 \$ /(\mathrm{kg} / \mathrm{s})^{1.2}$ & & $\$(\mathrm{~kg} / \mathrm{s})$
\end{tabular}


Table 4. General indications for the utilization as optimization criteria of NPV, IRR, PBP and PI in the evaluation of investments in CHP.

\begin{tabular}{ll}
\hline Indicator & Motivation \\
\hline NPV & $\begin{array}{l}\text { Maximization of the absolute value of the investment (e.g. amount of money } \\
\text { earned at the end of the investment life) }\end{array}$ \\
\hline PBP & Minimization of the capital risks associated with the investment \\
\hline IRR & Maximization of the rate of return of the specific investment \\
& Quantitative measurement of possible financial risks, if NPV is taken as \\
& decision parameter \\
\hline PI & Ranking of different investment alternatives \\
\hline
\end{tabular}

Table 5. Comparison of the profitability indicators for the best performances in the cases of "high" and "average" energy prices. NPV: $\beta=6, \mathrm{P}_{\mathrm{el}}=2.9 \mathrm{MW}$. IRR: $\beta=6, \mathrm{P}_{\mathrm{el}}=2.2 \mathrm{MW}$. PI: $\beta=6, \mathrm{P}_{\mathrm{el}}=2.2$ MW. Pay-Back: $\beta=6, P_{\mathrm{el}}=2.2 \mathrm{MW}$.

\begin{tabular}{ccc}
\hline Indicator & "Average” Scenario & "High” Scenario \\
\hline NPV (M€) & 12.0 & 14.8 \\
\hline IRR & $42 \%$ & $49 \%$ \\
\hline PI & 5.0 & 5.9 \\
\hline Pay-Back (Years) & 2.9 & 2.4 \\
\hline
\end{tabular}


b)

\section{Post-processing area}

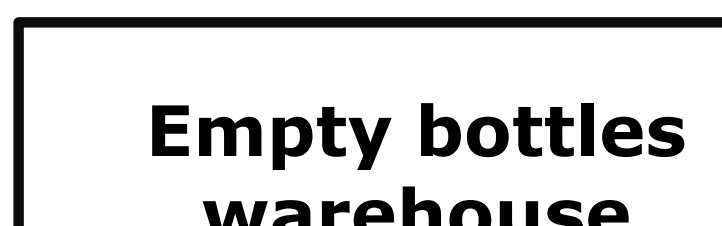

warehouse

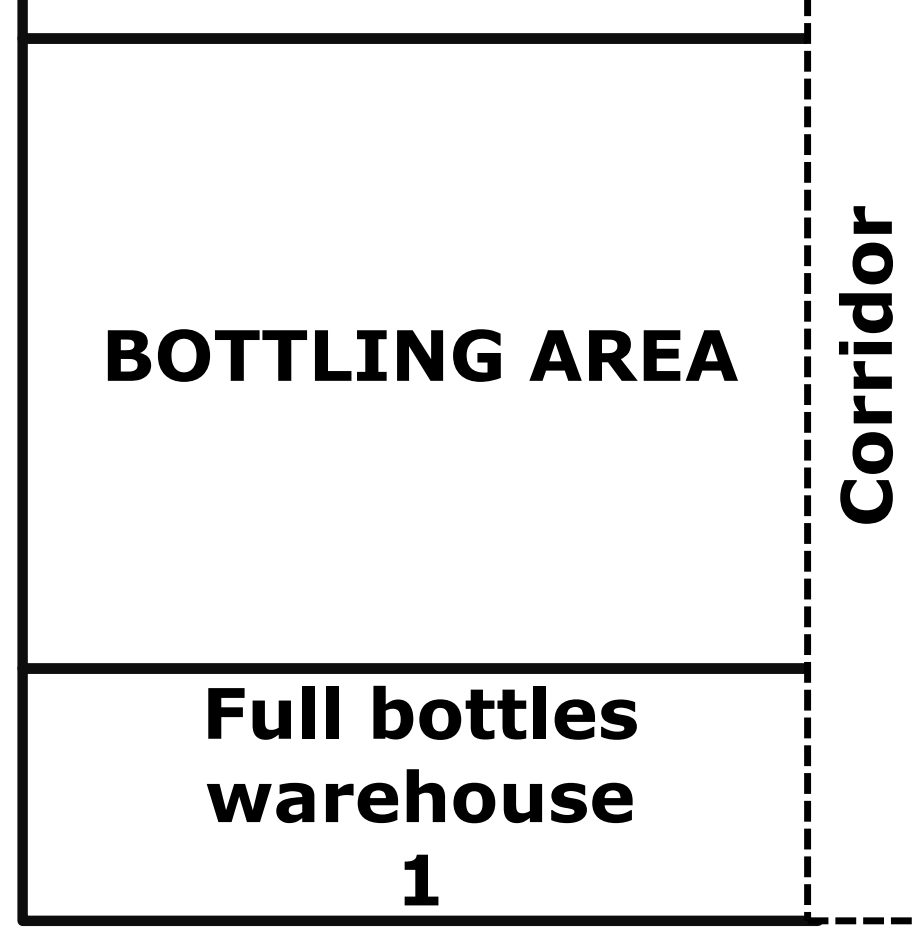

Processing area

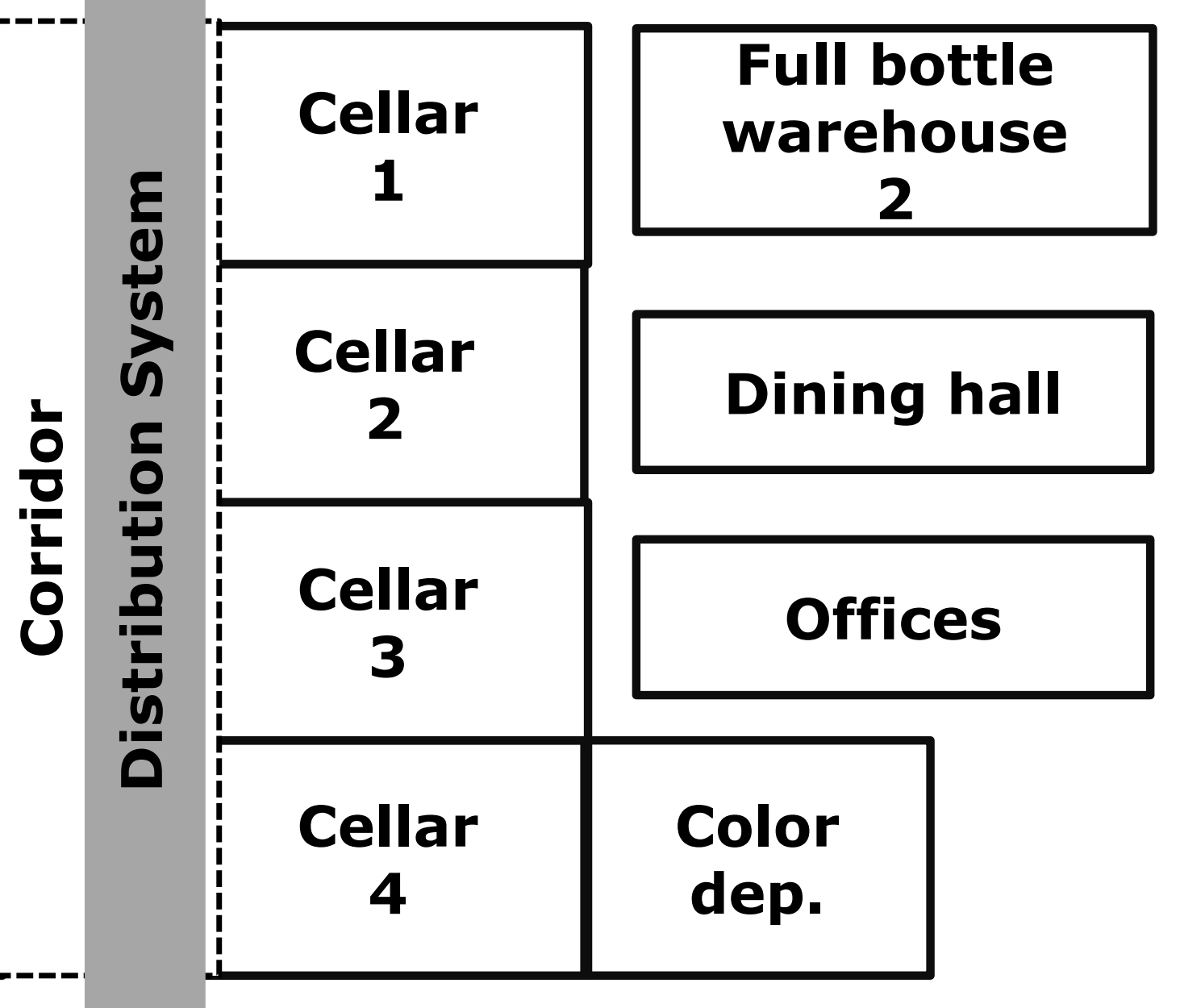

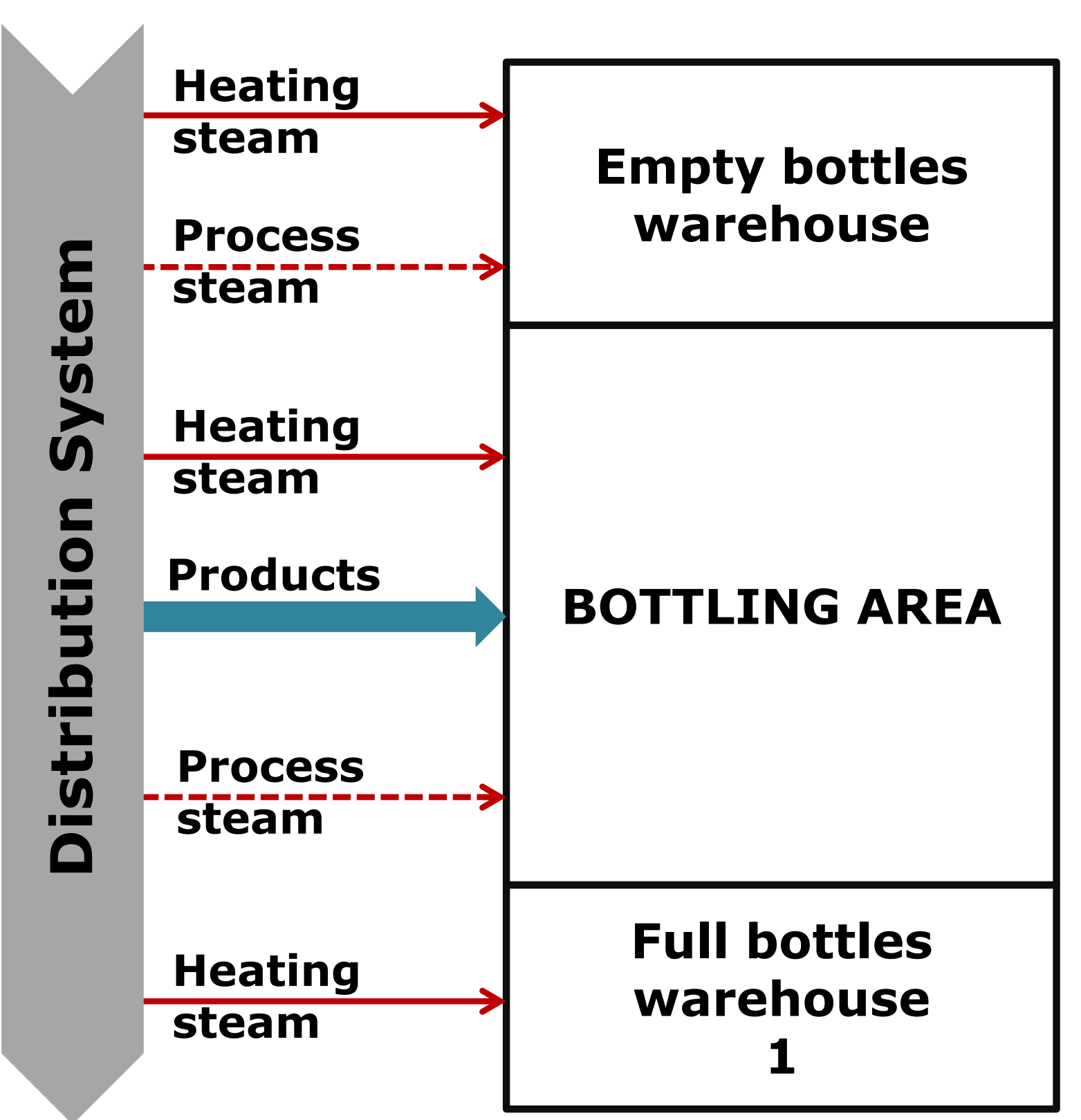


(a)

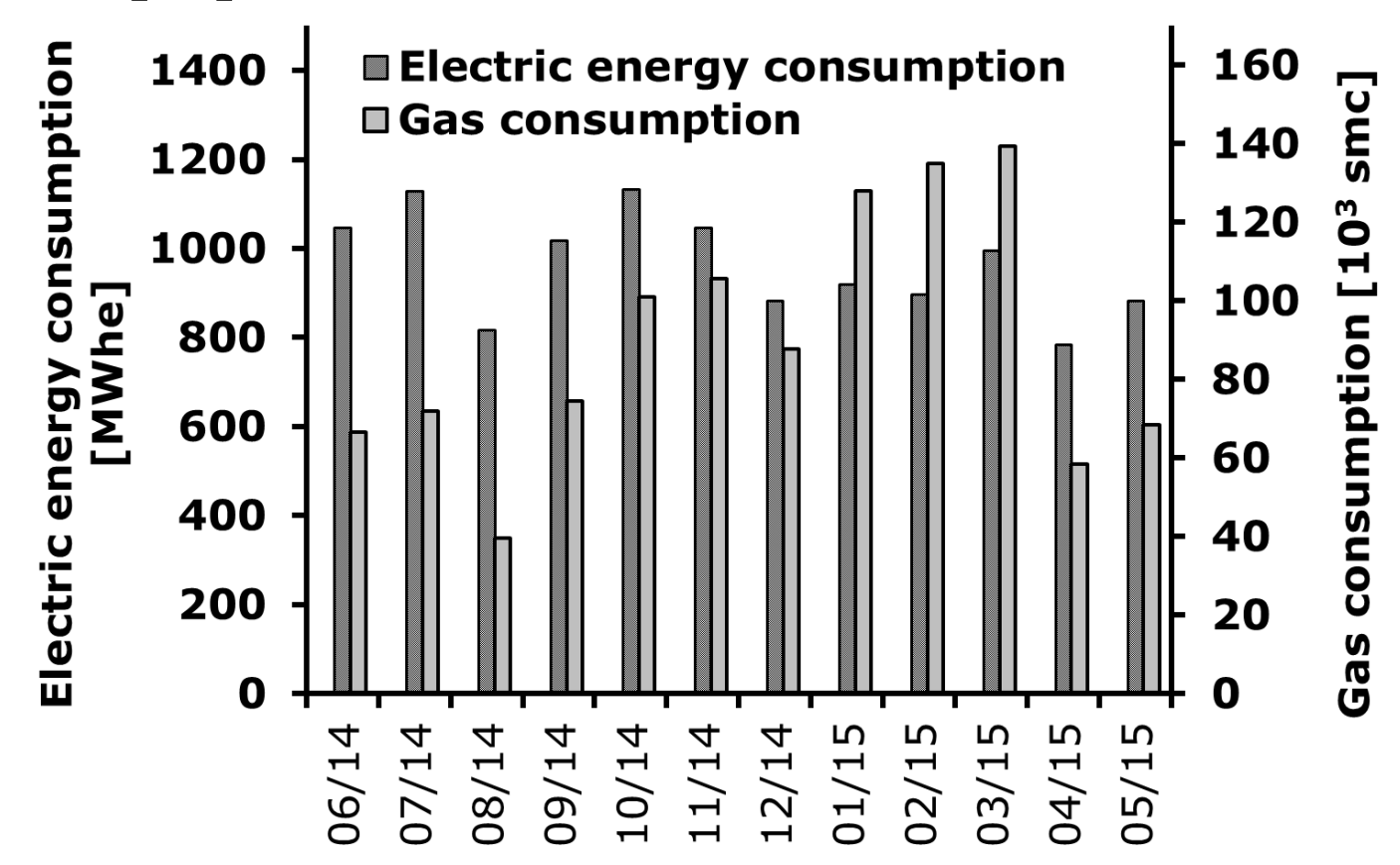

(b)

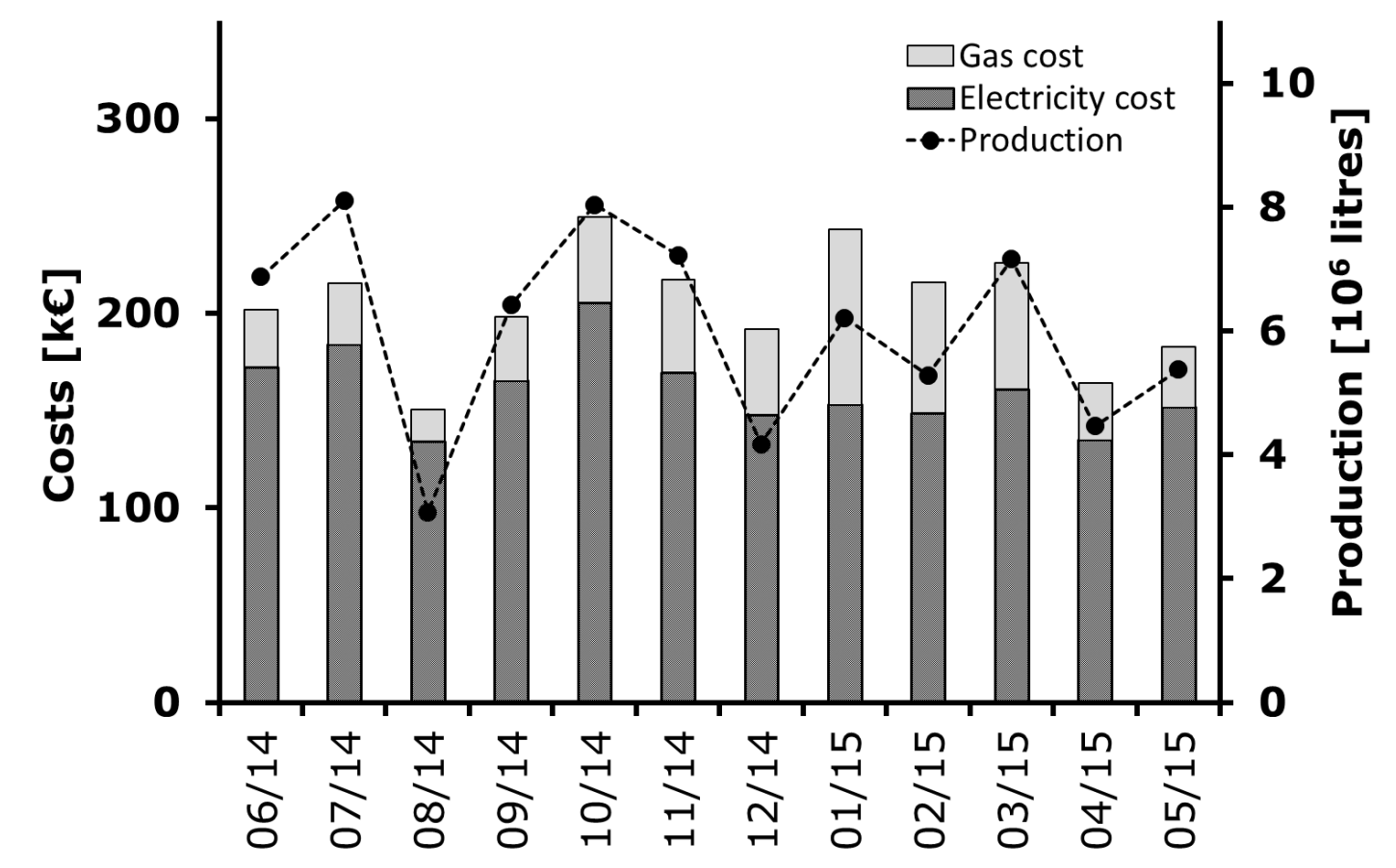

(c)

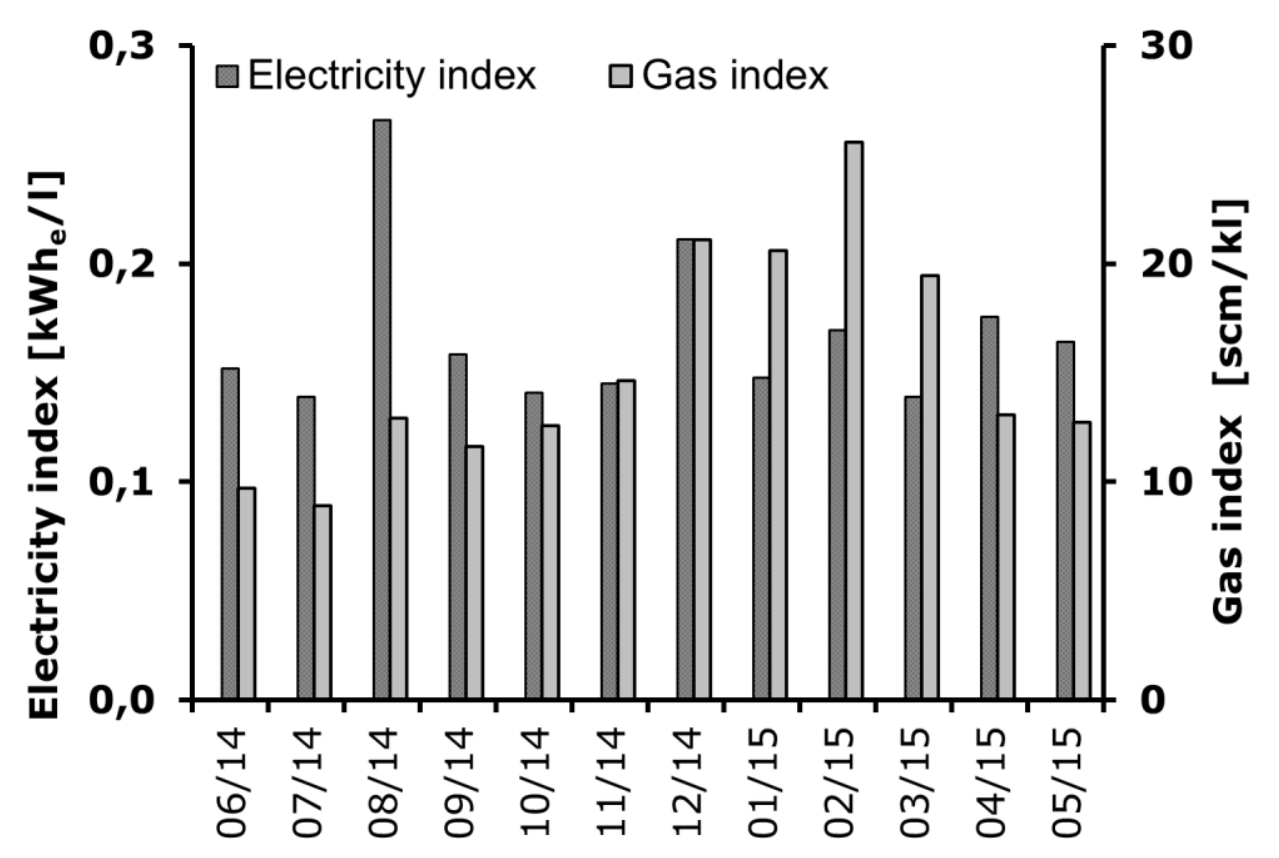


a)

a) Condenser
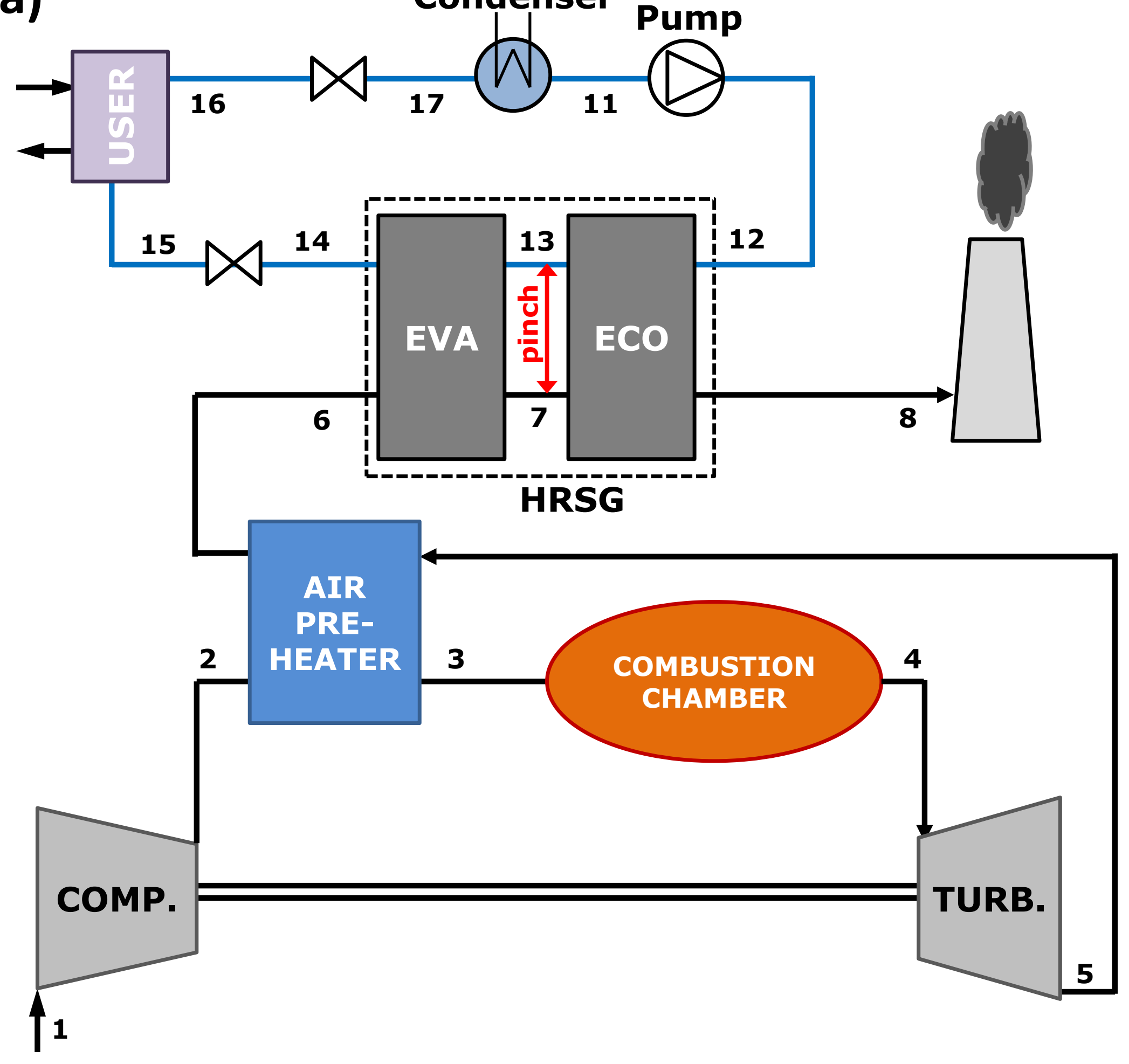

b)

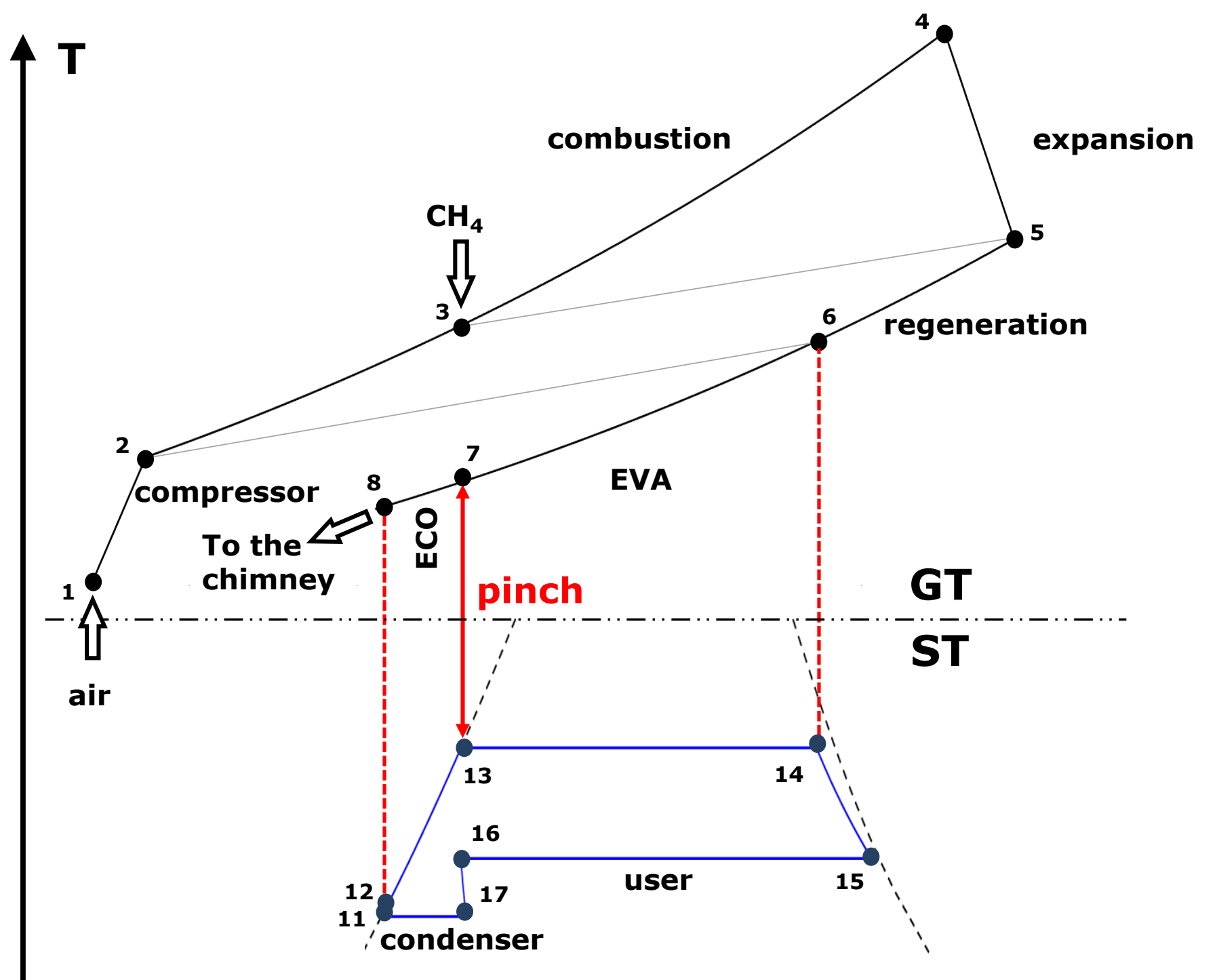



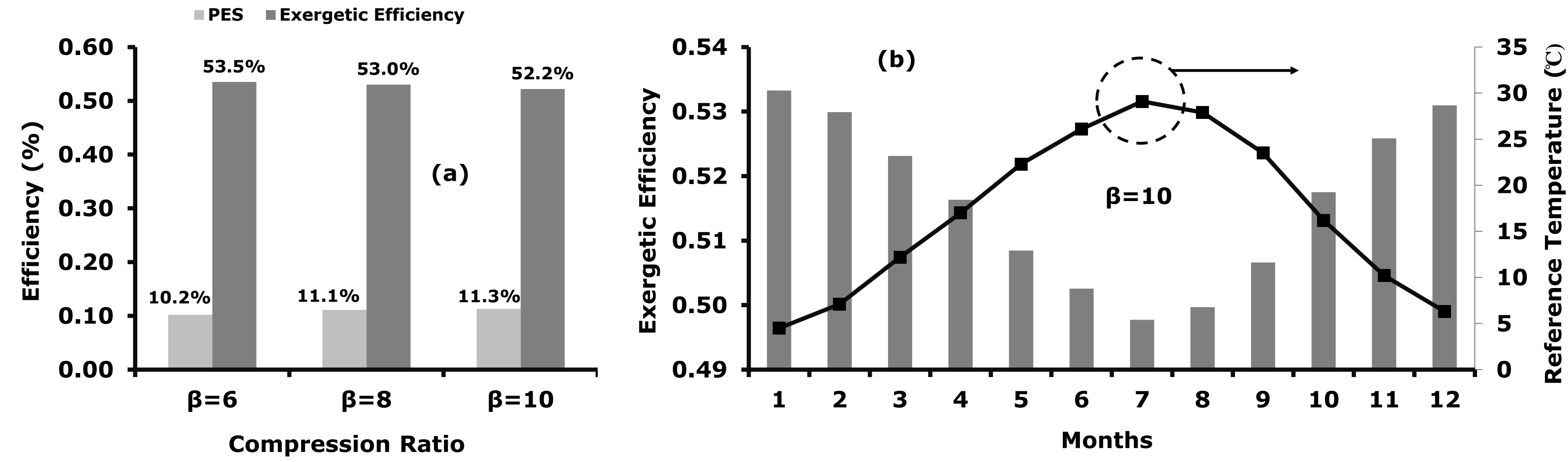


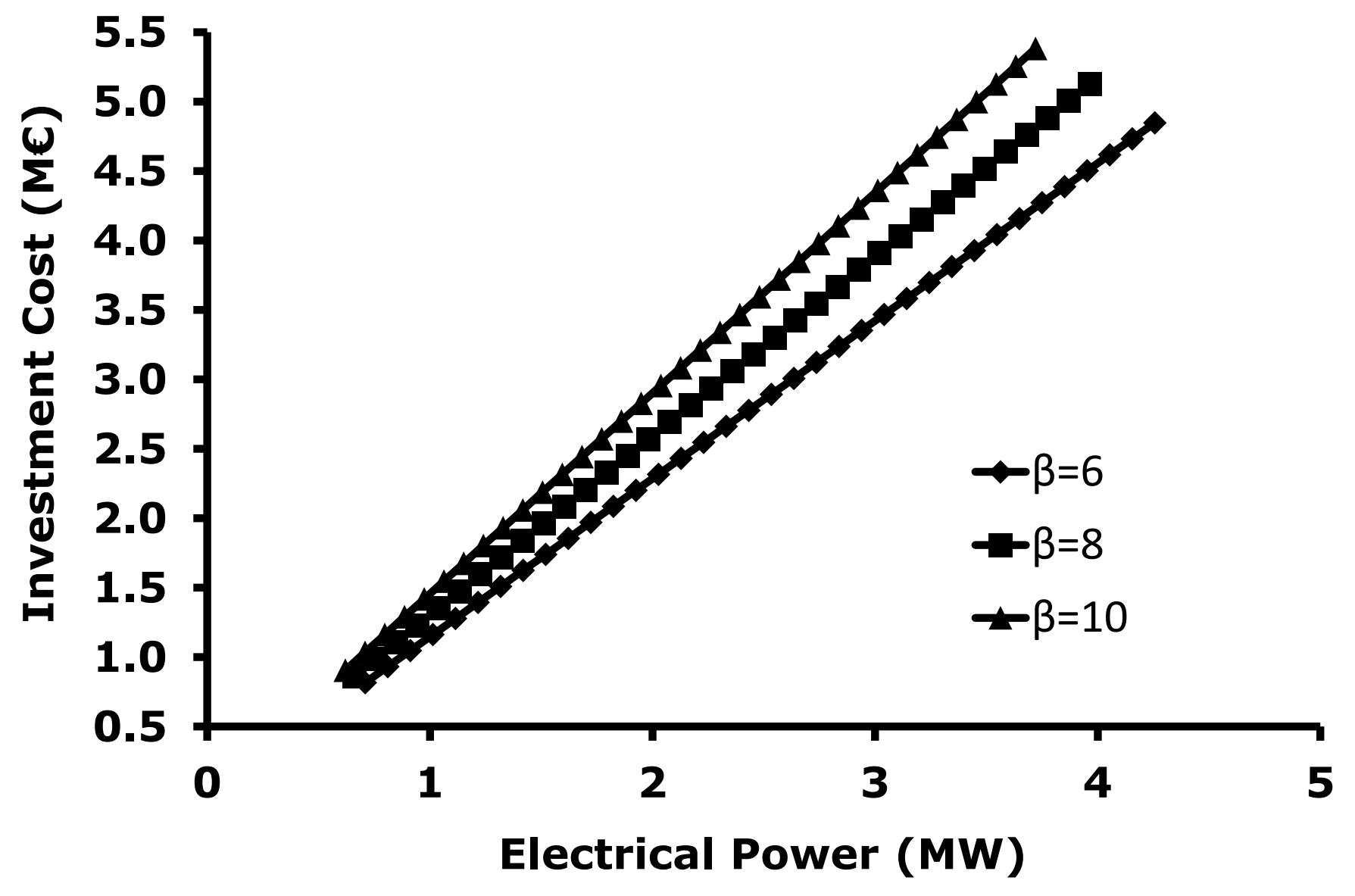



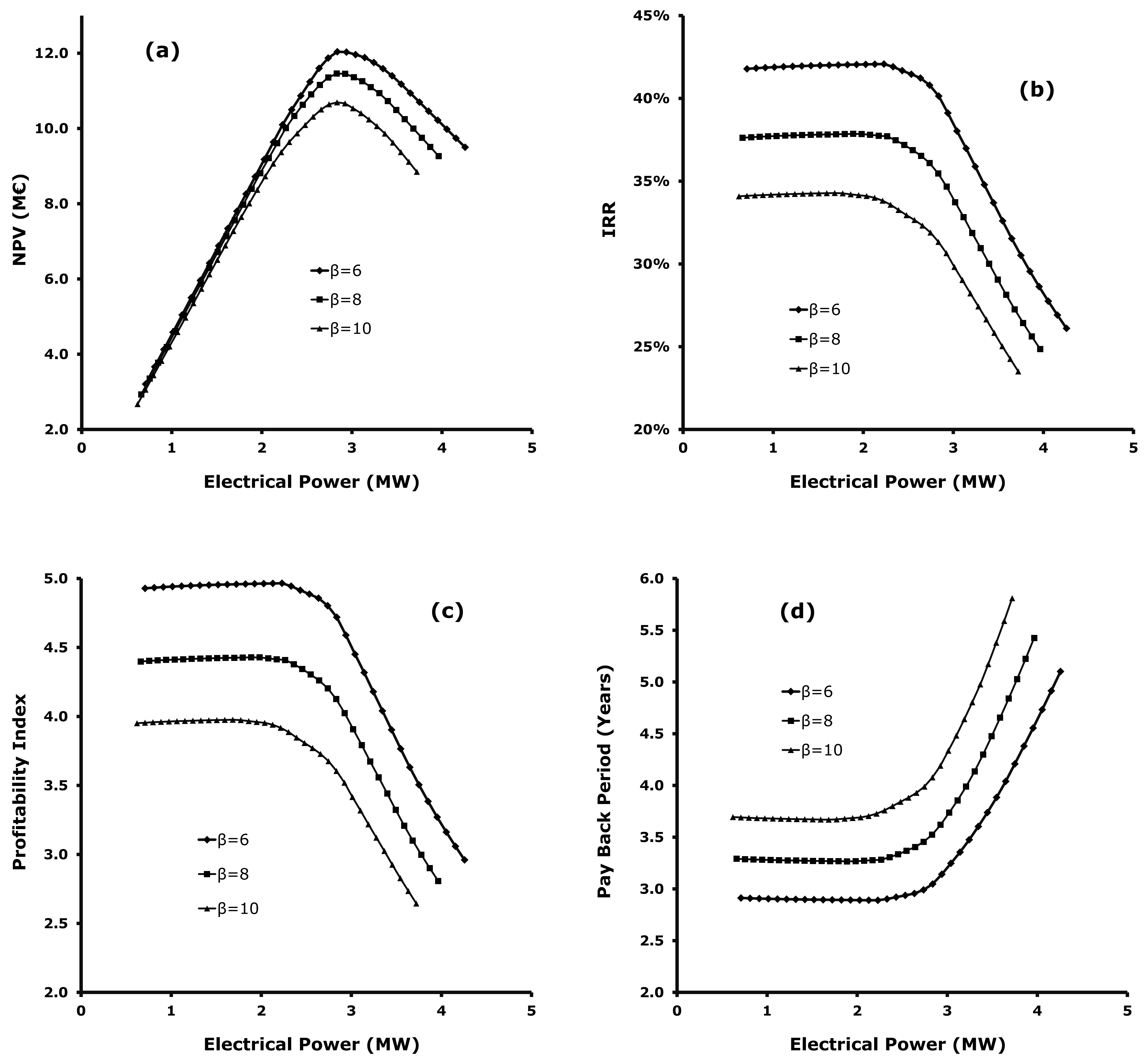

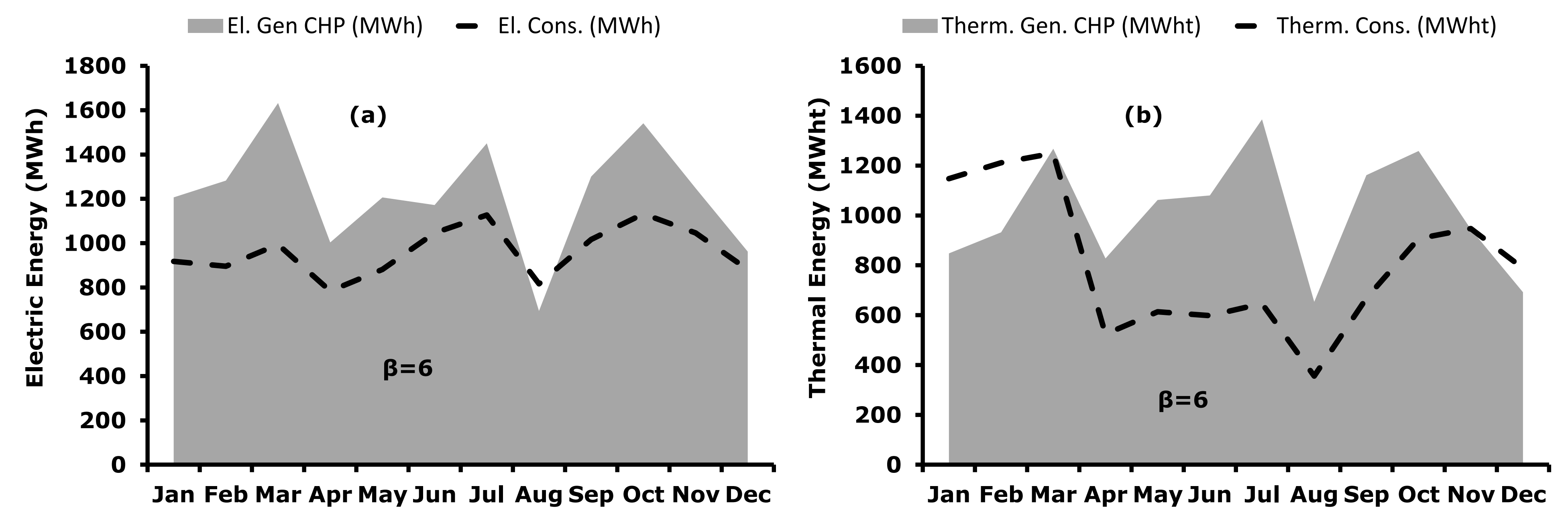


\section{Highlights}

- CHP utilization is demonstrated to allow a reduction of primary energy consumption

- The consideration of various investment indexes leads to the determination of different optimal powers

- The choice of a specific investment index to evaluate a CHP is linked to the strategy of the company 